\title{
A INFLUÊNCIA DA INTERFACE ENQUANTO SUPERFÍCIE NO USO DE JOGOS NO PROCESSO DE INCLUSÃO DIGITAL PARA $3^{\text {a IDADE }}$
}

\section{THE INFLUENCE OF THE INTERFACE WHILE SURFACE IN THE USE OF GAMES IN THE DIGITAL INCLUSION PROCESS FOR THE $3^{\text {RD }}$ $A G E$}

\author{
Mayckel Barbosa de Oliveira Camargo ${ }^{1}$, Esp. \\ Renata Svizzero Fakhoury ${ }^{2}$, Bel. \\ João Fernando Marar ${ }^{3}$, Dr. \\ Jacqueline Aparecida Gonçalves Fernandes de Castro ${ }^{4}$, Dra. \\ Susy Nazaré Silva Ribeiro Amantini ${ }^{5}$, Dra.
}

(1) Universidade Estadual Paulista - UNESP e-mail: mayckel.boc@gmail.com

(2) Universidade Estadual Paulista - UNESP e-mail: reefakhoury@gmail.com

(3) Universidade Estadual Paulista - UNESP e-mail:dr.fermarar@gmail.com

(4) Faculdades Integradas de Bauru - FIB e-mail:designcali@gmail.com

(5) Faculdades Integradas de Bauru - FIB e-mail: suamantini@gmail.com

Design de Superfície Digital, UX, $3^{\mathrm{a}}$ Idade

Com o envelhecimento, as pessoas são apresentadas gradativamente a diversos fatores inerentes à idade que por si só já caracterizam uma fase da vida que inspira cuidados, porém associado a todo este cenário, dentre uma vasta gama de pontualidades, pode-se vislumbrar um fenômeno muito presente em nosso cotidiano: a exclusão desta faixa populacional ao meio digital. Uma via de amenização deste problema são os projetos de inclusão digital para a $3^{\text {a }}$ idade. Assim como qualquer outra atividade pedagógica, estes cursos precisam estar não só adaptados ao contexto temporal e social, mas também ao público ao qual ele se destina. Dando continuidade a estudos prévios sobre a inserção de jogos em projetos de inclusão digital para idosos, este estudo tem como objetivo analisar a influência da interface enquanto um projeto de Design de Superfície significante na percepção do usuário idoso em um projeto de 


\section{$16^{\circ}$ \\ ERGODESIGN USIHC CINAHPA}

$16^{\circ}$ Ergodesign - Congresso Internacional de Ergonomia e Usabilidade de Interfaces Humano Tecnológica: Produto, Informações Ambientes Construídos e Transporte

$16^{\circ}$ USIHC - Congresso Internacional de Ergonomia e Usabilidade de Interfaces Humano Computador

CINAHPA | 2017 - Congresso Internacional de Ambientes Hipermídia para Aprendizagem.

inclusão digital para idosos da cidade de Bauru, interior do Estado de São Paulo, Brasil.

Digital Surface Design, UX, Elderly

With aging, people are presented gradually to various age-related factors that in themselves already characterize a life-like phase that inspires care, but associated with this whole scenario, from a wide range of punctualities, one can glimpse to very present in our daily Life: the exclusion of this population to the digital environment. One way to alleviate this problem is to include digital inclusion projects for the elderly. Like any other pedagogical activity, this courses need to be adapted not only to the temporal and social context, but also to the audience for which it is intended. This paper aims to analyze the influence of the interface waiting a project of Surface Design in perception of the elderly user in a project of digital inclusion in the city of Bauru, inside of the State of São Paulo, Brazil.

\section{Introdução}

Segundo o Instituto Brasileiro de Geografia a Estatística em 2016 a população brasileira contava com cerca de $8,17 \%$ de idosos com 65 anos ou mais em sua composição (IBGE, 2017). Isso significa aproximadamente 16,8 milhões de senhores e senhoras que acabam enfrentando inúmeras situações pertinentes a idade avançada como, por exemplo, diminuição na capacidade motora, problemas de visão, problemas de cognição e memória e até mesmo problemas de interação interpessoal. De acordo com Veras (2012) esses idosos apresentam uma maior carga de doenças e incapacidades que por si só caracterizam uma fase da vida que requer cuidados, porém hoje temos um fator agravante: a tecnologia, ou melhor conceituando, o mundo tecnológico.

Esses idosos que vem de uma geração analógica, em muitos casos acabaram não acompanhando a evolução da tecnologia e hoje se encontram exclusos a esse meio digital. Uma das soluções para minimização deste apartamento social são iniciativas de inclusão digital para a terceira idade.

Assim como qualquer iniciativa educacional, estes processos têm que estar além de adaptados ao meio, adequados também ao público ao qual se destina. Podemos observar como forte tendência educacional o uso de gamificação na relação de ensino - aprendizagem, onde o professor mediador faz uso dos, propriamente ditos, jogos ou de processos e características dos mesmos para uma maior efetividade e afetividade no ensino.
Para Morin et al (2003), a característica indispensável para o ensino trata-se do desejo, prazer e amor pela atividade proposta, onde processos gamificados tendem a ampliar positivamente a experiência do usuário, e nesse processo de positivação a interface enquanto superfície tem impacto direto em sua efetividade. Essa superfície digital, complexa e líquida, é composta por representações e símbolos que fazem relações diretas ou indiretas ao cotidiano para guiar a intencionalidade do usuário ao longo da atividade. De acordo com Formiga, o uso de ícones, símbolos e pictogramas como signos de informação faz com que esta comunicação seja democrática e facilitada (FORMIGA, 2011).

\section{Aspectos teóricos}

\subsection{Sociedade Tecnológica e $3^{a}$ idade}

Analisando o contexto contemporâneo, mais especificamente o período posterior à revolução industrial ocorrida entre o final do séc. XVIII e início do séc. XIX, a sociedade tem estado no centro de intensas alterações comportamentais e ideológicas. Alvin Toffler, em seu livro "A Terceira Onda" de 1980, disse que existem novas regras para esta nova vida, construída perante uma economia e meios de comunicação massificados sobre novas estruturas sociais e familiares. Mudanças cotidianas são simbolizadas quando ocorrem grandes mudanças históricas.

Em virtude disto, a Revolução Industrial foi responsável por modificações não só na vida social, econômica e familiar das pessoas, mas 


\section{$16^{\circ}$ \\ ERGODESIGN USIHC CINAHPA}

também por ocasionar diferenças emocionais e provocar alterações no modo de pensar e no cotidiano da população (LOPES, 2008). Porém, as mudanças aceleraram junto com as novidades trazidas pelas máquinas, e essas foram motivos de discussões e dúvidas quanto a sua melhoria. A sociedade passou do sistema agrário para o sistema fabril, sendo marcada por transformações nos meios de produção, onde as cidades ganharam forma e se consolidaram como grandes centros populacionais.

Junto com a migração do campo em destino às cidades, essa sociedade fabril foi evoluindo para uma realidade cada vez mais tecnológica e digital sendo impulsionada pelos avanços da tecnologia, que agora não demoram mais décadas para ocorrer, mas sim poucos anos, quando não poucos meses.

Ao longo dessas mudanças históricas, sociais, econômicas e comportamentais, o objeto passou por modificações quanto as suas necessidades. Como um reflexo dessa sociedade altamente tecnológica e em constante e acelerada transformação, no final da década de 70 e início da década de 80 , a mais notória teoria pós-industrial pode ser observada com a interpretação da sociedade moderna pelo termo Sociedade da Informação (KUMAR, 2006), buscando classificar e elucidar esta nova formação social, onde a informação se torna a matéria prima e com a crescente convergência de tecnologias, esse fluxo informacional é gerado e, em constante trânsito a partir dos mais diversos meios, ganha destaque e notoriedade (CASTELLS, 2000). Como consequência de um período de transição, quando se fala em utilização da tecnologia, percebe-se uma sociedade mista dividida em três grandes grupos: o primeiro com uma geração que já estava adulta no momento da popularização tecnológica, mas que foi treinada e se adaptou a esta nova realidade; o segundo com uma geração que já nasceu em meio a este mundo digital e como tal não precisa de treinamento, pois trata a tecnologia como algo natural. E um terceiro, como um grande e importante grupo que compreende as pessoas de idade mais avançada, que por conta dos mais diversos motivos acabaram ficando alheios a essa modernização. $16^{\circ}$ Ergodesign - Congresso Internacional de Ergonomia e Usabilidade de Interfaces Humano Tecnológica: Produto, Informações Ambientes Construídos e Transporte

$16^{\circ}$ USIHC - Congresso Internacional de Ergonomia e Usabilidade de Interfaces Humano Computador

CINAHPA | 2017 - Congresso Internacional de Ambientes Hipermídia para Aprendizagem.
Mendes (2006) diz que os desejos e as aspirações das pessoas mudam junto com os meios tecnológicos. As novas tecnologias de informação e comunicação (TICs) não mudam apenas os modos de vida das pessoas, mas transformam também o modo como elas interagem, percebem e se relacionam com o ambiente. Devido às mudanças tecnológicas, o idoso dos dias atuais é cada vez mais ativo, ou seja, tem sua capacidade de produzir e consumir elevadas, assim como têm tido uma maior participação em mudanças sociais e políticas. Com a crescente demanda da necessidade do uso dessas novas tecnologias, o idoso tem tentado deixar de lado o isolamento e a alienação e se tornar cada vez mais inserido na era digital. Desta forma, a inclusão digital na terceira idade aparece de modo a integralizar esta parcela da sociedade com o mundo contemporâneo.

De acordo com Bizelli et al (2009) as alterações acarretadas pela melhora na qualidade de vida são causadas por aumento dos estímulos cognitivos, das atividades motoras e musculares, e também pelas boas vivências da aproximação social, presencial e tecnológica.

As dificuldades aparecem principalmente por todo, ou quase todo, o tempo de vivência desses idosos ter ocorrido sem o uso do computador e outros artefatos tecnológicos. Muitos deles temem a utilização da tecnologia ou se afastam pela ideia de complexidade, desmotivando e desestimulando-os ainda mais. Por isso, o modo de introdução e explicação deve exigir muita calma, cuidado e uma boa comunicação.

\subsection{Jogos}

\subsubsection{Do entretenimento à educação}

Cada dicionário terá sua própria definição, cada enciclopédia sua própria caracterização e cada estudioso sua própria convicção sobre a definição de jogo. Essa pluralidade de fato já era esperada para a definição de uma palavra com tão vasta aplicação quanto esta, mas fazendo um amplo resumo, jogos são atividades voluntárias orientadas por regras que criam um contexto simulativo, podendo facilmente ser distinto da "vida real" com

\section{Realização: - -) UNIVERSIDADE FEDERAL




\section{$16^{\circ}$ \\ ERGODESIGN USIHC CINAHPA}

elementos suficientes para cativar e obter atenção total dos participantes, havendo ainda a possibilidade de ser praticado por uma única pessoa ou por várias, em grupos ou individualmente (ABT, 1987).

No universo dos jogos temos diversas classificações e reclassificações de acordo os aspectos observados. Se analisado sob o prisma da intencionalidade podemos dividir os jogos em dois grandes grupos: os jogos de entretenimento que tem como função primária o entretenimento propriamente dito e os jogos educativos que partilham de muitas técnicas dos jogos de entretenimento, mas que de acordo com Chen e Michael (2006), tem como objetivo primário não a diversão, e sim o processo de aprendizagem. Independente de qual categoria a atividade pertença, os jogos podem ser jogados a sério ou casualmente. No caso dos jogos sérios, mesmo tendo sido explícita e cuidadosamente pensados para fins educativos e não pretenderem ser jogados primariamente para diversão, não significa que os jogos educativos não são, ou não deveriam ser, divertidos.

Huizinga (2007) diz em seu livro que o ato de jogar é a base para toda a cultura, filosofia, direito e aspectos da cultura humana. Pensando nisto, tende-se a tornar natural seu uso para os mais diversos propósitos além do entretenimento, como por exemplo, para fins educacionais. Um interessante exemplo da efetividade do uso de jogos para fins sérios trata-se do jogo America's Army, onde seu intuito era passar os valores do exército americano e despertar o interesse em jovens de 16-24 anos em se alistarem para o exército americano.

As forças armadas americanas precisam de 80.000 novos recrutas a cada ano e cerca de $15 \%$ desta necessidade vem sendo preenchida por candidatos proveniente do jogo. Sua versão inicial foi modificada e hoje serve como ferramenta de treinamento tanto para os novos recrutas como para soldados experientes. Com essa ferramenta os batalhões podem se preparam para missões praticando como desarmar bombas, simulando confrontos e resultados. Com isso tem-se o $16^{\circ}$ Ergodesign - Congresso Internacional de Ergonomia e Usabilidade de Interfaces Humano Tecnológica: Produto, Informações Ambientes Construídos e Transporte

$16^{\circ}$ USIHC - Congresso Internacional de Ergonomia e Usabilidade de Interfaces Humano Computador

CINAHPA | 2017 - Congresso Internacional de Ambientes Hipermídia para Aprendizagem.

benefício de soldados mais bem capacitados e preparados diminuindo as chances de baixas nos campos de batalhas reais (CHEN; MICHAEL, 2006).

\subsubsection{Interface enquanto superficie}

Garrett (2011) define a experiência do usuário a partir da interface de um software ou aplicativo como um conjunto de cinco camadas onde a mais externa é definida pela superfície (Figura 1), que se comporta como porta de entrada do usuário para a interação sendo exteriorizada pelo visual. Nela estão representados direta ou indiretamente todos os elementos necessários à realização das atividades propostas de uma maneira concreta e direcional para o entendimento por parte do usuário.

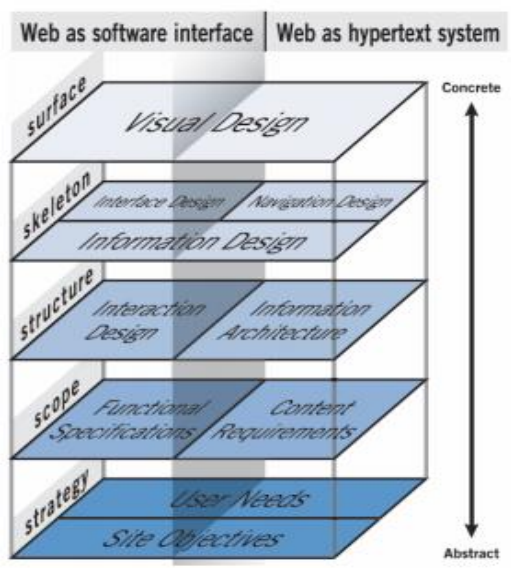

Figura 1: Elementos da experiência do usuário á partir da interface por Garrett

Essa interface sendo analisada enquanto superfície, configura-se por um meio intencionalmente planejado e composto por símbolos gráficos de linguagem verbal e não verbal, carregados de significados diretamente ligados ao repertório comunicacional dos observadores, no caso os usuários.

A percepção consiste em processos cerebrais que atrelam significados a estímulos sensoriais permitindo que através desta percepção o ser humano se organize, coordene e interprete os estímulos sensoriais na atribuição de significados (CASTRO, 2016). Segundo Formiga (2009), a 


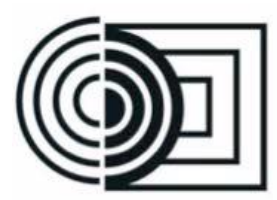

percepção e consequente resposta aos símbolos por parte do usuário são delimitadas e definidas por fatores físicos e psicológicos conhecidos como fatores ergonômicos, onde para que a comunicação seja correta e satisfatoriamente compreendida o usuário deve dominar o respectivo repertório ou a mensagem deve ser clara a ponto de causar uma compreensão imediata abstendo-se do repertório do receptor.

\section{Materiais e Métodos}

O protocolo de avaliação foi estruturado em duas atividades constituídas de uma tarefa e um questionário para avaliação de aspectos subjetivos do sujeito em relação à tarefa recém realizada. $\mathrm{Na}$ primeira atividade foi proposto aos sujeitos que pintassem um desenho, previamente selecionado, utilizando o programa padrão de desenho do sistema operacional Windows 7, o Microsoft Paint (Figura 2), enquanto na segunda atividade era proposto similarmente ao ocorrido na primeira tarefa, que os sujeitos colorissem um desenho, também previamente selecionado, mas agora utilizado um jogo específico chamado "pintar a arvore de natal" (Figura 2), distribuído gratuitamente para acesso online através do link <https://goo.gl/0Y2MLp>, que simula os livros de colorir físicos. Tanto na primeira como na segunda atividade, os sujeitos contaram com 10 minutos para realizar cada. $16^{\circ}$ Ergodesign - Congresso Internacional de Ergonomia e Usabilidade de Interfaces Humano Tecnológica: Produto, Informações Ambientes Construídos e Transporte

$16^{\circ}$ USIHC - Congresso Internacional de Ergonomia e Usabilidade de Interfaces Humano Computador

CINAHPA | 2017 - Congresso Internacional de Ambientes Hipermídia para Aprendizagem.

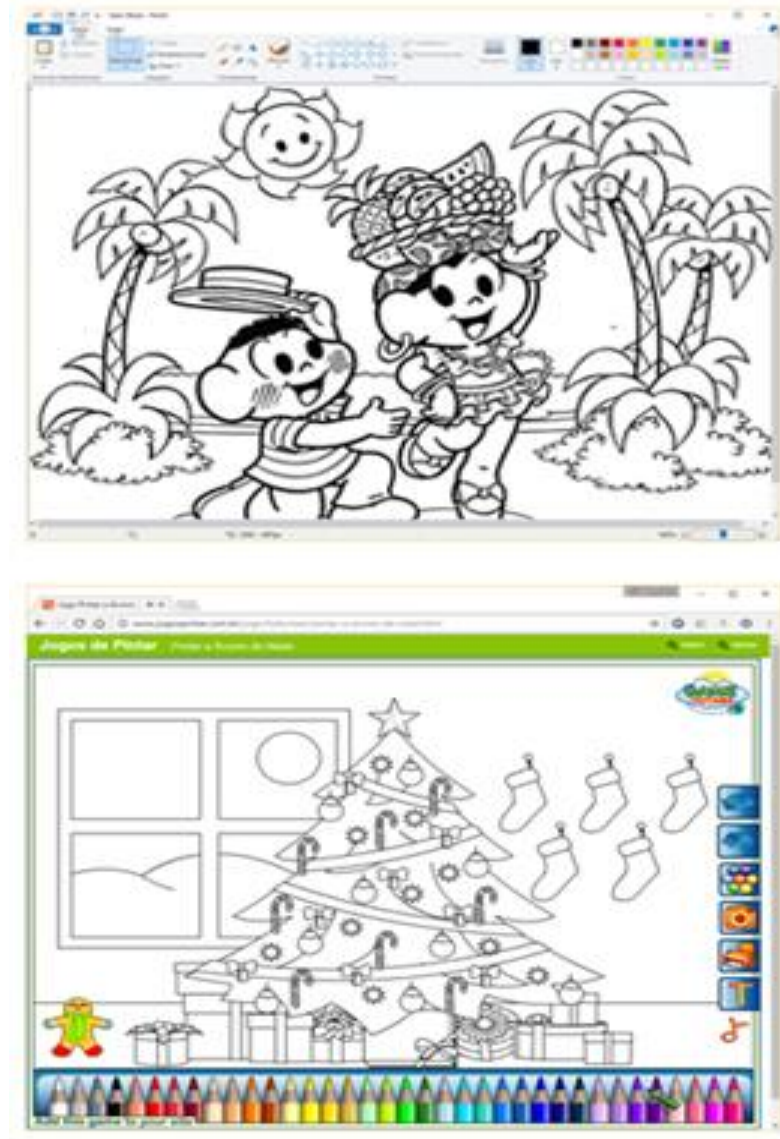

Figura 2: acima tela da atividade 1 e abaixo tela da atividade 2

O questionário foi composto por 3 questões sendo que, a primeira foi destinada a verificar se o sujeito ficou perdido ou confiante durante a atividade, a segunda através da técnica do diferencial semântico, com 3 pares de adjetivos, observados no quadro 1 , destinada à verificação de aspectos subjetivos de percepção do usuário em relação à tarefa e, por último, a terceira questão intencionada à verificar se os sujeitos repetiriam ou não a atividade em casa. No questionário aplicado pósatividade 2, foi acrescida uma questão para identificar em qual das duas atividades os sujeitos gostaram e se sentiram mais motivados.

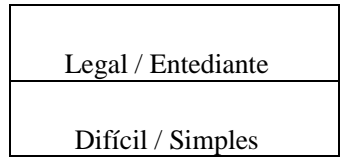

Realização:

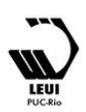




\section{$16^{\circ}$ \\ ERGODESIGN USIHC CINAHPA}

Bonita / Sem graça

Quadro 1: Pares de adjetivos utilizados no diferencial semântico

Yin (2001) coloca que o protocolo em um estudo de caso é mais do que um instrumento. Ele contém os procedimentos e diretrizes que devem ser seguidas durante todo o experimento, sendo ele uma das principais ferramentas para aumentar a confiabilidade de um estudo de caso. Com isso, para garantir uma maior possibilidade de sucesso na realização do estudo, o protocolo foi previamente testado com três voluntários para eventuais correções do procedimento.

Como voluntários para a pesquisa, foram convidados os alunos do curso " 3 a Idade Conectada", um projeto de inclusão digital para a $3^{\mathrm{a}}$ idade, realizado pela Assomary, a Associação dos Moradores do Mary Dota, um bairro da cidade de Bauru localizada no interior do Estado de São Paulo, constituindo uma amostragem de 7 idosos.

O protocolo foi aplicado em março de 2017, de forma coletiva na própria sala de informática da associação (Figura 3), onde os idosos rotineiramente têm suas aulas contando com três mediadores para garantir seu bom andamento e controle. Todo o protocolo foi filmado com uma câmera posicionada para pegar toda a sala, proporcionando uma melhor análise posterior e controle. Para que todo o procedimento fosse correto, os sujeitos leram, concordaram e assinaram o Termo de Consentimento Livre e Esclarecido (TCLE) para participação na pesquisa e autorização do uso de sua imagem para fins exclusivamente acadêmicos. $16^{\circ}$ Ergodesign - Congresso Internacional de Ergonomia e Usabilidade de Interfaces Humano Tecnológica: Produto, Informações Ambientes Construídos e Transporte

$16^{\circ}$ USIHC - Congresso Internacional de Ergonomia e Usabilidade de Interfaces Humano Computador

CINAHPA | 2017 - Congresso Internacional de Ambientes Hipermídia para Aprendizagem.

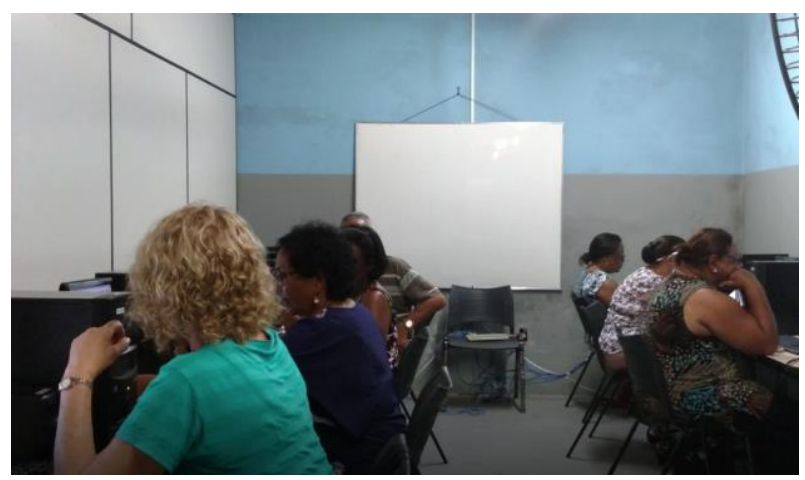

Figura 3: Sujeitos durante a aplicação do protocolo

O protocolo teve duração de aproximadamente 30 minutos, contando com sua realização sem intercorrências. Vale observar que o preenchimento dos questionários pós-atividade foi acompanhado pelos aplicadores a fim de garantir o melhor grau de esclarecimento possível em relação às questões e sua forma correta de preenchimento.

\section{Análise e Discussão}

Além a coleta de dados por meio dos questionários pós-atividade também foi realizada a observação participante, que tem sido usada por pesquisadores nos últimos anos para coletar dados e percepções a respeito de facetas dos sujeitos, que podem não ser tão facilmente visualizadas utilizando-se de outros métodos; identificar os resultados de processos específicos, e documentar os eventos fisiológicos e psicológicos (PATERSON; BOTTORFF; HEWAT, 2003), tornando desta maneira o ato de observar atentamente os detalhes e colocar o pesquisador como parte integrante da realidade observada de forma que ele possa entender a complexidade dos aspectos psicossociais, permitindo ao mesmo, um diálogo mais eficiente com o grupo estudado (ZANELLI, 2002).

Na primeira atividade, mesmo os idosos já tendo usando o programa Microsoft Paint previamente nas aulas do curso de inclusão, se mostraram apreensivos e consideravelmente perdidos, necessitando e solicitando a intervenção dos aplicadores para a realização da tarefa. As principais dúvidas levantadas foram como selecionar o balde de tinta, e principalmente, como proceder no processo de seleção da cor e pintura.
Realização:

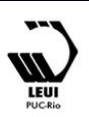




\section{$16^{\circ}$ \\ ERGODESIGN USIHC CINAHPA}

Nesta atividade alguns sujeitos questionaram mais de uma vez como se realizavam estes procedimentos. Como percebido pelos aplicadores e posteriormente constatado na gravação do protocolo, a sala encontrava-se em uma sutil profusão sonora e percebia-se um ambiente de leve tensão por parte dos sujeitos em relação à atividade, vislumbrando-se também certa dificuldade de concentração para a manutenção da imersão na tarefa com vários dos sujeitos dispersando-se ao longo do período.

Na segunda atividade, apesar de os sujeitos não terem entrado em contato prévio com o jogo proposto, a assimilação do processo de pintura foi praticamente instantâneo. Logo no começo da tarefa, os sujeitos identificaram que precisariam pegar o lápis de cor para pintar o desenho e o fizeram de maneira intuitiva. Mesmo levantando dúvidas iniciais de "como pintar", percebeu-se que as questões levantadas eram muito mais de cunho auto-afirmativo do que solicitações de ajuda, como por exemplo, a colocação do sujeito 1 dizendo em uma entonação mais elevada "precisa pegar o lápis para pintar né?", mesmo sem qualquer orientação. Claramente pode observar-se uma sala mais silenciosa e concentrada na atividade. Durante os dez minutos de aplicação, notou-se que os sujeitos estavam mais focados no que estavam fazendo, menos tensos e mais serenos. Ao longo desta segunda atividade as questões levantadas pelos sujeitos não mais eram sobre a utilização da interface e mesmo sobre o processo de realização, mas sim sobre questões emocionais e afetivas como, por exemplo, que cor usar em cada item do desenho.

Comparando o processo - problema identificado na primeira atividade em relação à mecânica do processo selecionar ferramenta $->$ escolher a cor -> pintar o desenho, percebe-se que o mesmo não ocorreu na segunda atividade onde esta mecânica além de simplificada para escolher o lápis de cor > pintar o desenho, também estava representado por signos mais representativos no contexto apresentado. Essa diferença de representação da interface enquanto superfície visual, que pode ser observada na figura 4 sugere que, quanto mais simples e intuitivo for esta composição, de mais $16^{\circ}$ Ergodesign - Congresso Internacional de Ergonomia e Usabilidade de Interfaces Humano Tecnológica: Produto, Informações Ambientes Construídos e Transporte

$16^{\circ}$ USIHC - Congresso Internacional de Ergonomia e Usabilidade de Interfaces Humano Computador

CINAHPA | 2017 - Congresso Internacional de Ambientes Hipermídia para Aprendizagem. fácil cognição e significação ela será para o usuário. Diversos estudos comprovam esta relação de efetividade entre a cognição e a rápida interpretação no que se refere composição da superfície permeando pelo design informacional o que pode também ser efetivamente observada na amostragem de um público idoso.

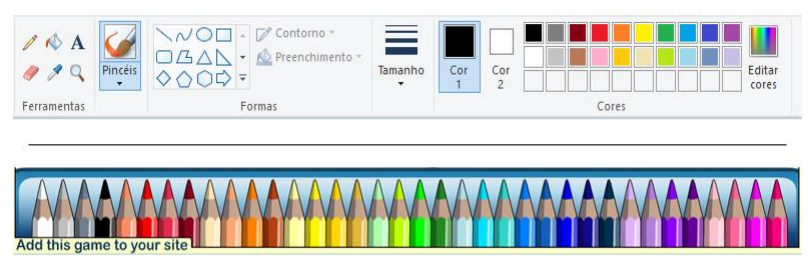

Figura 4: Diferença de representação na interface visual entre a primeira atividade (acima) e a segunda atividade (abaixo)

Analisando os dados coletados nos questionários de avaliação pós-atividade, a questão 1, que se destinava a revelar o quanto os sujeitos sentiram-se perdidos ou confiantes durante as atividades, mostrou que $57,14 \%$ se declararam plenamente confiantes na primeira atividade frente à $85,71 \%$ observado na atividade 2 . O ponto neutro, mostrando que o usuário não se sentiu nem perdido e nem confiante, mas sim, indiferente à atividade manteve-se em $14,29 \%$. Interessante também observar que na primeira atividade, 14,29\% dos avaliados se declararam parcialmente ou completamente perdidos, enquanto na atividade 2 estes dois itens obtiveram $0 \%$ das respostas, como observado no gráfico 1 .

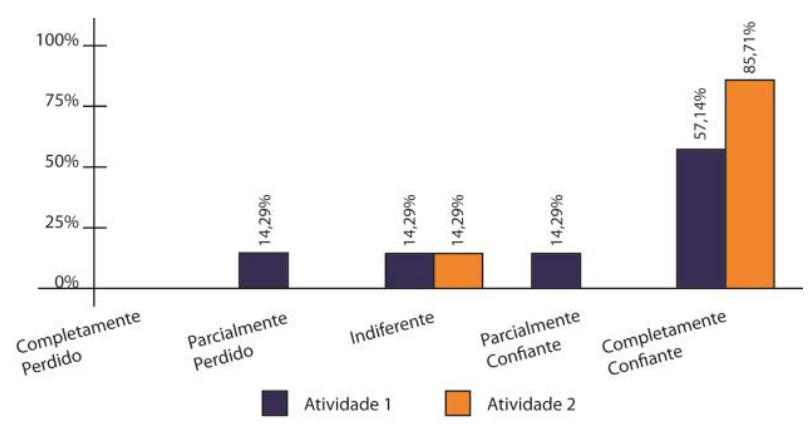

Gráfico 1: Sensação de perda ou confiança durante a atividade

No primeiro item da segunda questão, os sujeitos foram convidados a classificar gradualmente entre 


\section{$16^{\circ}$ \\ ERGODESIGN USIHC CINAHPA}

legal ou entediante a atividade realizada. Enquanto em relação à segunda atividade, $100 \%$ dos sujeitos a classificaram como completamente legal, na primeira atividade, $14,29 \%$ a classificaram como completamente entediante e o restante como completamente legal (Gráfico 2).

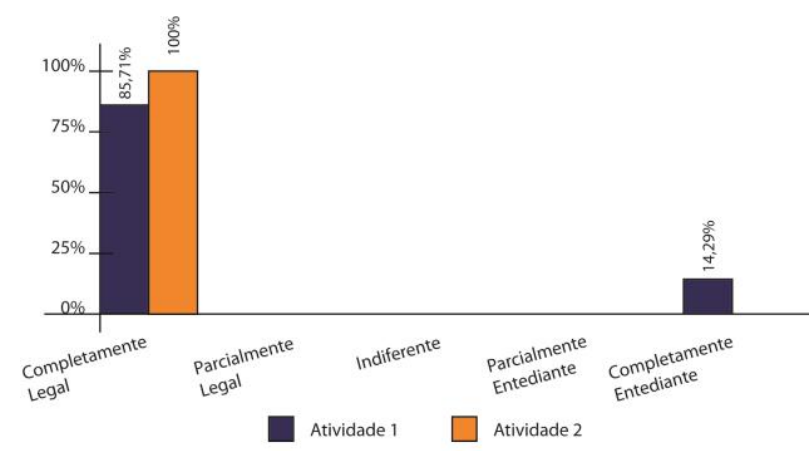

Gráfico 2: Percepção da atividade entre "legal" e "entediante"

No gráfico 3 pode-se observar o segundo item da questão 2 , que intencionava mensurar a percepção de complexidade da atividade, tanto na primeira quanto na segunda tarefa nenhum sujeito declarou achar completa ou mesmo parcialmente difícil, porém enquanto na primeira os sujeitos se dividiram em $28,57 \%$ indiferentes, $14,29 \%$ acharam parcialmente simples e apenas $57,14 \%$ completamente simples, na segunda atividade, $85,71 \%$ dos avaliados declararam ter achado atividade completamente simples e apenas $14,29 \%$ se mantiveram indiferentes não considerando nem difícil e nem fácil a atividade.

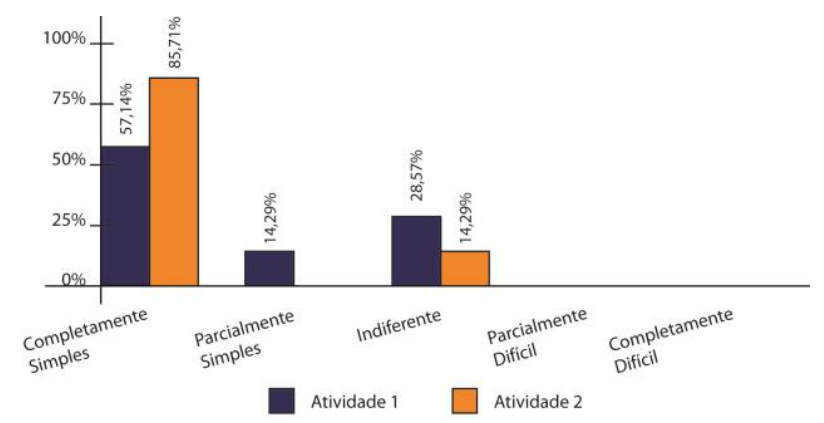

Gráfico 3: Percepção de facilidade ou dificuldade durante a atividade $16^{\circ}$ Ergodesign - Congresso Internacional de Ergonomia e Usabilidade de Interfaces Humano Tecnológica: Produto, Informações Ambientes Construídos e Transporte

$16^{\circ}$ USIHC - Congresso Internacional de Ergonomia e Usabilidade de Interfaces Humano Computador

CINAHPA | 2017 - Congresso Internacional de Ambientes Hipermídia para Aprendizagem.

O último item da questão 2 convidava os sujeitos a classificarem as atividades entre "bonita" e "sem graça". $100 \%$ dos sujeitos classificaram a primeira atividade como completamente bonita enquanto $14,29 \%$ classificaram a segunda atividade como parcialmente bonita, como pode ser observado no gráfico 4.

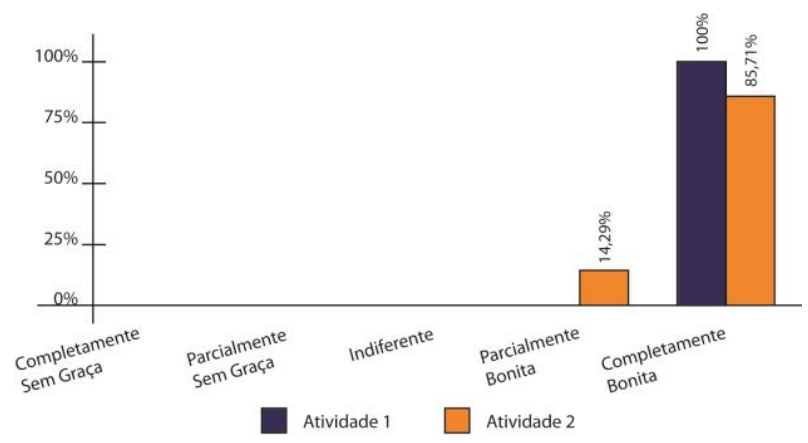

Gráfico 4: Percepção da atividade entre "Sem Graça" e "Bonita"

Quando questionados na questão 3, sobre a possibilidade de realização da atividade voluntariamente em casa, $100 \%$ dos sujeitos afirmaram que com certeza repetiriam a atividade 1 em casa, enquanto $85,71 \%$ repetiriam com certeza a atividade 2 e 14,29\% declararam que havia a possibilidade de realização da segunda tarefa em casa.

Em uma última questão para avaliar a preferência dos sujeitos entre as duas atividades, $85,71 \%$ declararam se sentir mais à vontade e motivado na segunda atividade preferindo-a (Gráfico 5).

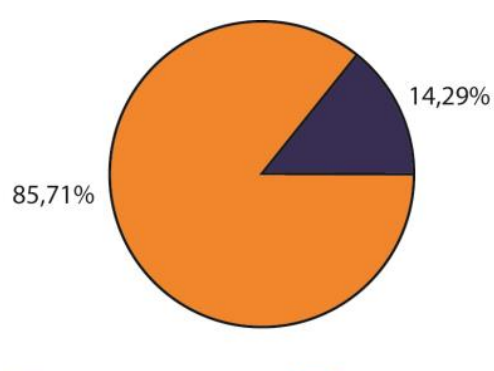

Atividade 1 Atividade 2

Gráfico 5: Preferência entre a primeira e a segunda atividade
Realização:
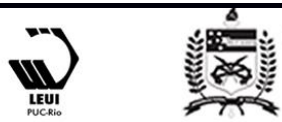


\section{$16^{\circ}$ \\ ERGODESIGN USIHC CINAHPA}

Observando a totalidade das percepções levantadas, identifica-se uma tendência a uma melhor relação entre os sujeitos e a segunda atividade se comparada à primeira, tendo como fator influenciador a concepção da superfície. Um ponto que chamou a atenção dos aplicadores foi o fato de o sujeito 3 , durante toda a atividade 2 mostrar sutis indícios de ansiedade e, comprovado no questionário, ter preferido a atividade 1 , mesmo claramente achando a segunda atividade mais fácil. Quando questionado informalmente sobre o motivo, o sujeito revelou que em sua religião eles não comemoravam aniversários, e consequentemente, para eles não existia o natal. $\mathrm{O}$ fato da atividade 2 utilizar justamente a temática do natal a deixou desconfortável, sendo esse o motivo de predileção a atividade 1 . Com isso é possível observar que além da interface enquanto superfície visual mostra-se também, a interface enquanto superfície significante como fator influenciador para a experiência do usuário idoso, revelando a importância da adequação simbólica da atividade proposta ao contexto do público ao qual se destina como comprova Castro (2007) quando diz que, a percepção é simples e puramente guiada por interesses pessoais, de um grupo cultural ou uma sociedade.

\section{Considerações finais}

Durante o protocolo pode-se perceber a influência da interface enquanto superfície na positivação da experiência do usuário idoso como um meio facilitador para sua relação com a tecnologia. Enquanto na primeira atividade realizada com um programa padrão, contendo uma interface corporativa e não adaptada ao público alvo, os sujeitos mostraram-se apreensivos, durante a realização da segunda atividade utilizando uma interface lúdica e adaptada ao contexto proposto, a tensão previamente percebida se dissipou e convergiu para um ambiente tranquilo, onde cada sujeito estava focado na sua atividade e principalmente, não mais preocupado com a mecânica de realização da atividade, mas sim envolvido emocionalmente com a tarefa proposta tornando aquela realização algo prazeroso, o que pode ser percebido pela reação dos idosos que chegaram solfejar baixinho algumas canções $16^{\circ}$ Ergodesign - Congresso Internacional de Ergonomia e Usabilidade de Interfaces Humano Tecnológica: Produto, Informações Ambientes Construídos e Transporte

$16^{\circ}$ USIHC - Congresso Internacional de Ergonomia e Usabilidade de Interfaces Humano Computador

CINAHPA | 2017 - Congresso Internacional de Ambientes Hipermídia para Aprendizagem.

durante a aplicação do jogo.

Não basta criar projetos e iniciativas de inclusão digital para a $3^{\mathrm{a}}$ idade simplesmente com o intuito de letramento digital, esses senhores e senhoras precisam de muito mais do que apenas saber utilizar a tecnologia que os cerca. Em muitos casos esses idosos precisam também encontrar uma motivação para se imergir nessa tão famigerada sociedade da informação. Estudos prévios apontam possíveis potencialidades na realização de cursos de inclusão para $3^{\mathrm{a}}$ idade tendo em sua metodologia a utilização de jogos (CAMARGO; FAKOURY; MARAR, 2016). Em continuidade a essa linha de pensamento, com os resultados observados nesta pesquisa, pode-se observar que a interface, enquanto superfície visual mostra-se um fator determinante na positivação da experiência do usuário idoso, colaborando para que as atividades sejam menos vistas como tarefas e mais percebidas como momentos prazerosos onde, o idoso se envolve emocionalmente, aumentando a sua imersão no contexto proposto.

\section{Referências Bibliográficas}

ABT, C. C. Serious Games. Boston: University Press of America, 1987. 176p.

BIZELLI, M. H. S. S. et al. Informática para a Terceira idade: características de um curso bem sucedido. Revista Ciência em Extensão, v. 5, n. 2, p. 4-14, 2009.

CAMARGO, M. B. O; FAKOURY, R. S.; MARAR, J. F. $3^{\text {a }}$ Idade Conectada: Um estudo piloto para a utilização de Serious Games na inclusão digital para idosos. In: III ENCONTRO MULTIDISCIPLINAR FAAG. Agudos: Editora ISE Ltda, 2016. P183-194.

CASTELLS, M. A sociedade em rede (trad. de Roneide Venâncio Majer). A era da informação: economia, sociedade e cultura, v. 1, 2000.

CASTRO, J. A. G. F. de. Design com identidade: por meio de estudos sócio-culturais e dos signos, 2007. Dissertação (Mestrado em Desenho
Realização:

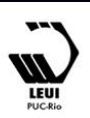




\section{$16^{\circ}$}

ERGODESIGN USIHC CINAHPA

$16^{\circ}$ Ergodesign - Congresso Internacional de Ergonomia e Usabilidade de Interfaces Humano Tecnológica: Produto, Informações Ambientes Construídos e Transporte

$16^{\circ}$ USIHC - Congresso Internacional de Ergonomia e Usabilidade de Interfaces Humano Computador

CINAHPA | 2017 - Congresso Internacional de Ambientes Hipermídia para Aprendizagem.

Industrial) - Universidade Estadual Paulista: Bauru, 2007.

CASTRO, Jacqueline. Sistema Delineador em Design de Superfície para significação e identidade arquitetônica corporativa. Tese (doutorado em Arquitetura, Tecnologia e Cidade) Universidade Estadual de Campinas: Campinas, 2016. 202p.

CHEN, S; MICHAEL, D. Serious Games: games that Educate, Train and Inform. Boston, Massachusetts: Thimson, 2006.

FORMIGA, Eliana. Símbolos Gráficos: Métodos de avaliação de compreensão. São Paulo: Bluncher, 2009. 148 p.

GARRETT, J. J. The elements of user experience: user-centred design for the web and beyond. Berkeley: Pearson Education, 2011.

Huizinga, J. Homo ludens: O jogo como elemento da cultura. São Paulo: Perspectiva, 2007.

IBGE, Projeção da população do Brasil e das unidades da federação. Disponível em: < http://www.ibge.gov.br/apps/populacao/projecao/> . Acesso em 21 de janeiro de 2017

KUMAR, K. Da sociedade pós-industrial à pósmoderna: novas teorias sobre o mundo contemporâneo. Rio de Janeiro: Jorge Zahar, 2006.

LOPES, J. R. B. Desenvolvimento e mudança social: formação da sociedade urbano-industrial no Brasil. Rio de Janeiro: SciELO books, 2008.

MENDES, C. F. Paisagem Urbana: uma mídia redescoberta. São Paulo: Editora Senac São Paulo, 2006. 160 p.

MORIN, E., CIURANA, E., MOTTA, R. D. Educar na Era Planetária: O pensamento complexo como método de aprendizagem pelo erro e incerteza humana. São Paulo: Cortez, 2003
PATERSON, B. L.; BOTTORFF, J. L.; HEWAT, R. Blending observational methods: possibilities, strategies and challenges. International Journal of Qualitative Methods, v. 2, n. 1, p. 29-38, 2003.

TOFFLER, A. La tercera ola. Bogotá: Plaza \& Janes, 1980.

VERAS, R. Experiências e tendências internacionais de modelos de cuidado com o idoso. Ciência e Saúde Coletiva, v17, p. 231-238, 2012

YIN, R. K. Estudo de caso: planejamento e métodos. 2. ed. Porto Alegre: Bookman, 2001.

ZANELLI, J. C. Pesquisa qualitativa em estudos da gestão de pessoas. Estudos de Psicologia, v. 7, p. 79-88, 2002. 